\title{
Moringa oleifera extract enhances sexual performance in stressed rats"
}

\author{
Thawatchai PRABSATTROO ${ }^{\dagger 1,3}$, Jintanaporn WATTANATHORN ${ }^{\dagger \$ 2,3}$, Sitthichai IAMSAARD ${ }^{3,4}$, \\ Pichet SOMSAPT ${ }^{5}$, Opass SRITRAGOOL ${ }^{5}$, Wipawee THUKHUMMEE ${ }^{3}$, Supaporn MUCHIMAPURA ${ }^{2,3}$ \\ ( ${ }^{1}$ Graduate School and Department of Physiology (Neuroscience Program), Faculty of Medicine, Khon Kaen University, Khon Kaen 40002, Thailand) \\ $\left({ }^{2}\right.$ Department of Physiology, Faculty of Medicine, Khon Kaen University, Khon Kaen 40002, Thailand) \\ ( ${ }^{3}$ Integrative Complementary and Alternative Medicine Research and Development Center, Khon Kaen University, Khon Kaen 40002, Thailand) \\ $\left({ }^{4}\right.$ Department of Anatomy, Faculty of Medicine, Khon Kaen University, Khon Kaen 40002, Thailand) \\ ( ${ }^{5}$ Division of Nuclear Medicine, Department of Radiology, Faculty of Medicine, Khon Kaen University, Khon Kaen 40002, Thailand) \\ †E-mail: backwert@gmail.com; jintanapornw@yahoo.com \\ Received July 13, 2014; Revision accepted Oct. 31, 2014; Crosschecked Feb. 21, 2015
}

\begin{abstract}
Aphrodisiacs are required to improve male sexual function under stressful conditions. Due to the effects of oxidative stress and dopamine on male sexual function, we hypothesized that Moringa oleifera leaves might improve male sexual dysfunction induced by stress. Therefore, the effects on various factors playing important roles in male sexual behavior, such as antioxidant effects, the suppression of monoamine and phosphodiesterase type 5 (PDE-5) activities, serum testosterone and corticosterone levels, and histomorphological changes in the testes, of a hydroethanolic extract of $M$. oleifera leaves were investigated. Various doses of extract including 10, 50 , and $250 \mathrm{mg} / \mathrm{kg}$ body weight (BW) were given orally to male Wistar rats before exposure to $12 \mathrm{~h}$-immobilization stress for $7 \mathrm{~d}$. The results demonstrated that the extract showed both antioxidant and monoamine oxidase type B (MAO-B) suppression activities. At $7 \mathrm{~d}$ of treatment, the low dose of extract improved sexual performance in stress-exposed rats by decreasing intromission latency and increasing intromission frequency. It also suppressed PDE-5 activity, decreased serum corticosterone level, but increased serum testosterone, numbers of interstitial cells of Leydig and spermatozoa. The increased numbers of interstitial cells of Leydig and spermatozoa might have been due to the antioxidant effect of the extract. The increased sexual performance during the intromission phase might have been due to the suppression of MAO-B and PDE-5 activities and increased testosterone. Therefore, $M$. oleifera is a potential aphrodisiac, but further research concerning the precise underlying mechanisms is still needed.
\end{abstract}

Key words: Moringa oleifera, Sexual behaviors, Stress doi:10.1631/jzus.B1400197

Document code: A

\section{Introduction}

Sexual feeling and sexual activity are inevitable parts of life, which play an important role in the sur-

\footnotetext{
"Corresponding author

* Project supported by the Higher Education Research Promotion and National Research University Project of Thailand, Office of the Higher Education Commission, through the Food and Functional Food Research Cluster of Khon Kaen University (No. NRU541061) and the Integrative Complementary Alternative Medicine Research and Development Center, Khon Kaen University, Thailand

(10) ORCID: Thawatchai PRABSATTROO, http://orcid.org/0000-00016292-9040; Jintanaporn WATTANATHORN, http://orcid.org/00000002-7383-2348

(C) Zhejiang University and Springer-Verlag Berlin Heidelberg 2015
}

CLC number: R698 vival of the human race (Kothari, 2001). Since sex is a most intimate, indispensable, and integral part of every individual's life and can be a source of pleasure and fulfillment, sexual dysfunction can induce depression, anxiety, and debilitating feelings of inadequacy (Kennedy et al., 1999; Baldwin, 2001). Although male sexual dysfunction is not a life threatening disorder, it can greatly affect the quality of life. It has been reported that about $20 \%-30 \%$ of men suffer from sexual dysfunction (Lewis et al., 2004). Because of its high impact and high prevalence, a great effort has been made to search for effective interventions to protect against sexual dysfunction. 
Sexual function is a complex process involving the brain, hormones, emotions, nerves, muscles, and blood vessels. It is very sensitive to stress. Therefore, stressful lifestyles or events usually induce sexual dysfunction. It has been reported that chronic physical and psychological stresses modulate neurotransmission in the median preoptic area and decrease penile blood flow, resulting in erectile dysfunction (Santosh et al., 2011). Experimental stress induced by restraint can suppress testicular steroidogenesis, giving rise to a reduction in plasma testosterone (Orr and Mann, 1990). Long term exposure to stress destroys interstitial cells of Leydig and decreases serum testosterone and spermatogenesis (Rai et al., 2004). Stress also increases the activity of the hypothalamopituitary-adrenal axis (HPA-axis), leading to the enhanced plasma cortisol and increased sympathetic system function (Carrasco and van de Kar, 2003). This leads to excessive oxidative stress and stressrelated disorders (Ahmad et al., 2012) including sexual dysfunction (Orr and Mann, 1990).

To date, most available drugs in the market target at the intromission phase, the most common phase of sexual dysfunction. The most popular drugs are sildenafil citrate, vardenafil and tadalafil citrate, which target the suppression of phosphodiesterase type 5 (PDE-5), which in turn increases penile blood flow and penile tumescence. Unfortunately, these drugs have serious side effects such as sudden hypotension, hypersensitivity reaction, myalgia, abnormal vision, and infertility (Fauci et al., 2005). Since the current therapeutic drugs do not target all phases of the sexual responsive cycle and produce serious side effects, a novel strategy is required, which is cheap, easy to apply, and less toxic.

Various herbs known to be aphrodisiacs have long been used for enhancing sexual desire and sexual performance in traditional folklore. They can exert their actions at various targets such as the neuroendocrine system, which plays a crucial role in sexual motivation and function (Hull et al., 1997; Meston and Frohlich, 2000), and PDE-5, an important enzyme in the signal pathway which regulates penile erection via the regulation of cavernous smooth muscle tone, which in turn controls penile blood flow (Andersson, 2001). Several lines of evidence show that testosterone and dopamine can control male sexual function both at the nervous system and at the penis (Hull et al., 1997). In addition, a recent study has shown that oxidative stress also plays a role in the impairment of carvernosal function and the pathophysiology of erectile dysfunction (Minhas et al., 2002; Hamed et al., 2003; de Young et al., 2004), and that antioxidants can improve erectile function (Zhang et al., 2011).

Moringa oleifera Lam. syn. M. ptreygosperma, or the drumstick tree, a widely consumed vegetable in Thailand, belongs to the Moringaceae family. It has long been used in nutritional, industrial, and medical fields. $M$. oleifera leaves are used for treating various ailments including constipation, headache, fever, and diabetes (Makonnen et al., 1997). In addition, it has been demonstrated that $M$. oleifera leaf extracts inhibit 6- $\beta$-hydroxylation of testosterone (Monera et al., 2008). Therefore, the sexual enhancing potential of this plant has gained attention. On the basis of the effects of dopamine and oxidative stress on male sexual function mentioned earlier, we hypothesized that $M$. oleifera leaves, which have antioxidant (Sreelatha and Padma, 2009) and monoamine modulation effects (Ganguly and Guha, 2008), might have beneficial effects on male sexual dysfunction induced by stress. Due to the limited supporting scientific data, we aimed to evaluate the sexual enhancing potential of $M$. oleifera by determining the effect of a hydroethanolic extract from M. oleifera leaves on various aspects of male sexual behavior in stressed rats, and to determine the effect of the extract on various factors involved in male sexual function, including the antioxidant effect, monoamine and PDE-5 suppression activities, serum testosterone and corticosterone levels, and histomorphological changes in the testes.

\section{Materials and methods}

\subsection{Chemicals and reagents}

Folin-Ciocalteu reagent, sodium carbonate, sodium acetate, $\mathrm{FeCl}_{3} \cdot 6 \mathrm{H}_{2} \mathrm{O}$, aluminum chloride, potassium acetate, bovine serum albumin, tannic acid, 1,1-diphenyl-2-picrylhydrazyl (DPPH), 2,4,6-tris (2-pyridyl)-s-triazine (TPTZ) (Fluka), clorgyline (selective MAO-A-I), tyramine, vanillic acid, and 4-aminoantipyrine were obtained from the SigmaAldrich Corporation, Ltd., Thailand. Gallic acid, 
ascorbic acid, and quercetin used were of analytical grade. A PDE-GloTM phosphodiesterase Assay Kit was purchased from the Promega Corporation, Thailand. Sildenafil citrate used in this study was from the Pfizer Company. All other substances were of analytical grade.

\subsection{Plant collection and extraction}

Fresh leaves of $M$. oleifera were harvested during November and December, 2011 from the Khon Kaen Province in Thailand. The plant specimen was authenticated by Assoc. Prof. Dr. Panee SIRISA-ARD, Faculty of Pharmaceutical Sciences, Chiangmai University, Thailand.

The leaves were homogenized as powder after being cleaned and dried at $60{ }^{\circ} \mathrm{C}$. The powder was extracted in $50 \%$ hydro-ethanolic solution using a maceration technique for $72 \mathrm{~h}$. The non-soluble part was separated using Whatman No. 1 filter paper. The filtrated extract was evaporated using a rotary evaporator. The yielded extract of $17.49 \%$ dry plant tissue was kept at $-20{ }^{\circ} \mathrm{C}$ until used. A voucher specimen was deposited at the Integrative Complementary Alternative Medicine Research and Development Center, Khon Kaen University, Thailand.

\subsection{Evaluation of total phenolic compounds and flavonoid content}

The total content of phenolic compounds was determined using the Folin-Ciocalteau method (Basma et al., 2011). In brief, the mixture, which contained $500 \mu \mathrm{l}$ of Folin-Ciocalteau reagent (10\%), $0.8 \mathrm{ml}$ of sodium carbonate $(7.5 \%, 0.075 \mathrm{~g} / \mathrm{ml})$ and $0.5 \mathrm{ml}$ distilled water (DW), was mixed with $0.2 \mathrm{ml}$ of $1 \mathrm{mg} / \mathrm{ml} \mathrm{M}$. oleifera leaf extract and left at room temperature in the dark for $45 \mathrm{~min}$. The optical density was read with an ultraviolet-visible spectrophotometer at $765 \mathrm{~nm}$. DW was used as a blank. The accuracy of data analysis was enhanced by using a triplicate-sample method. The total phenolic content (TPC) is expressed as mg of gallic acid equivalent (GAE)/g of dry weight, using the standard calibration line of gallic acid.

The total flavonoid content (TFC) was measured by aluminum chloride colorimetry (Pourmorad et al., 2006). A mixture containing $50 \%$ alcohol, $0.1 \mathrm{ml}$ of $10 \%$ aluminum chloride, $0.1 \mathrm{ml}$ of $1 \mathrm{~mol} / \mathrm{L}$ potassium acetate, and $2.8 \mathrm{ml}$ of DW was mixed with $0.5 \mathrm{ml}$ of the plant extract $(2 \mathrm{mg} / \mathrm{ml})$ and left at room temperature for $40 \mathrm{~min}$ in the dark. The absorbance at $415 \mathrm{~nm}$ was read using an ultraviolet-visible spectrophotometer. DW containing all the chemicals mentioned earlier except the plant extract, was used as the blank and each sample was prepared in triplicate. The mean value of the triplicate was used for analysis. The TFC is presented as mg of quercetin equivalent $(\mathrm{QE}) / \mathrm{g}$ of dry weight, using the standard calibration line of quercetin.

\subsection{Antioxidant assays}

Both DPPH and ferric reducing antioxidant power (FRAP) assays were carried out to determine the antioxidant activity of the extract. Stable free radical scavenging capacity was measured via the DPPH method (de Ancos et al., 2002) with a slight modification. In brief, $2.96 \mathrm{ml}$ of a $0.1 \mathrm{mmol} / \mathrm{L}$ solution of DPPH in methanol was incubated with $40 \mu$ of various concentrations of extract $(1.0,2.0,5.0,10.0$, 20.0 , and $25.0 \mathrm{mg} / \mathrm{ml}$ ) at room temperature for $30 \mathrm{~min}$. The decrease in DPPH radicals was evaluated by measurement of optical density at $515 \mathrm{~nm}$. The stable free radical scavenging capacity is presented as the percentage of inhibition of DPPH radicals $\left(I_{\mathrm{DPPH}}\right)$, calculated according to the following equation: $I_{\mathrm{DPPH}}=\left(A_{\mathrm{c}}-A_{\mathrm{s}}\right) / A_{\mathrm{c}} \times 100 \%$, where $A_{\mathrm{c}}$ and $A_{\mathrm{s}}$ are absorbances of control and sample, respectively.

To determine the FRAP, the reaction mixture containing FRAP solution $(300 \mathrm{mmol} / \mathrm{L}$ sodium acetate buffer $(\mathrm{pH} \mathrm{3.6)}, 10 \mathrm{mmol} / \mathrm{L}$ TPTZ solution in $40 \mathrm{mmol} / \mathrm{L} \mathrm{HCl}$, and $20 \mathrm{mmol} / \mathrm{L} \mathrm{FeCl}{ }_{3} \cdot 6 \mathrm{H}_{2} \mathrm{O}$ solution at a ratio of 10:1:1 (v/v)) (Thaipong et al., 2006) and $0.15 \mathrm{ml}$ of the dilution of the sample $(0.5 \mathrm{mg} / \mathrm{ml})$, was incubated at $37{ }^{\circ} \mathrm{C}$ in the dark for $30 \mathrm{~min}$. The optical density of the colored product (ferrous tripyridyltriazine complex) was measured at $593 \mathrm{~nm}$. Data are presented as $\mu \mathrm{mol}$ ascorbic acid equivalent (AAE) $/ \mathrm{g}$ extract.

\subsection{Amino acid determination}

Amino acid evaluation was performed according to the method of Nwidu et al. (2012). To hydrolyze peptide bonds, $1 \mathrm{ml}$ of $6 \mathrm{~mol} / \mathrm{L} \mathrm{HCl}$ and $0.08 \mathrm{ml}$ of $5 \%(\mathrm{v} / \mathrm{v})$ phenol/water solution were mixed with $5 \mathrm{mg}$ of extract and heated in a Pyrex tube with plastic Teflon-coated screw caps $(13 \mathrm{~cm} \times 1 \mathrm{~cm})$ at $110{ }^{\circ} \mathrm{C}$ for $72 \mathrm{~h}$. The solution was reheated in an oven at $70^{\circ} \mathrm{C}$, 
diluted with $1.0 \mathrm{ml}$ of sodium citrate buffer ( $\mathrm{pH} 2.2)$ and filtered through a GV Millex Unity filter (Millipore). The amino acid profile analysis was carried out by cation-exchange chromatography using an automated amino acid analyzer, Shimadzu LC-10A/C47A The sample was eluted by sodium, and post-column derivatization was performed using $o$-phthaldialdehyde (OPA). The retention time and area obtained by each amino acid were compared with those of standards to identify and quantify the amino acid profile.

\subsection{Determination of monoamine oxidase type $B$ (MAO-B) inhibition}

The MAO-B suppression effect was determined by spectrophotometry (Schurr and Livne, 1976). In brief, the rats were sacrificed by cervical dislocation and the cerebral cortices of healthy rats were removed and prepared as an homogenate with RIPA buffer $(50 \mathrm{mmol} / \mathrm{L}$ Tris- $\mathrm{HCl} \mathrm{pH} 7.4,150 \mathrm{mmol} / \mathrm{L} \mathrm{NaCl}$, $2 \mathrm{mmol} / \mathrm{L}$ ethylene diamine tetraacetic acid (EDTA), $0.5 \%$ sodium deoxycholate, $0.1 \%$ sodium dodecyl sulfate (SDS), and $1 \%$ Triton X-100) and centrifuged at $14000 \mathrm{~g}$ at $4{ }^{\circ} \mathrm{C}$ for $20 \mathrm{~min}$. After the centrifugation, the supernatant was harvested and served as the source of MAO-B. To initiate the enzyme reaction, $50 \mu \mathrm{l}$ of brain homogenate, preincubated with $50 \mu \mathrm{mol} / \mathrm{L}$ clorgyline (a selective inhibitor of MAO-A) at a ratio of $100: 1(\mathrm{v} / \mathrm{v})$, was added to the solution containing $2.75 \mathrm{ml}$ Tris buffer $(0.1 \mathrm{~mol} / \mathrm{L}, \mathrm{pH} 7.4)$ and $100 \mu \mathrm{l}$ of $0.1 \mathrm{~mol} / \mathrm{L}$ benzylamine (Holt et al., 1997; Dhingra and Goyal, 2008). The absorbance changes in the tested samples in the double beam spectrophotometer at a wavelength of $249.5 \mathrm{~nm}$ within 5 min were recorded against blanks containing Tris buffer and 5-hydroxytryptamine (Xu et al., 2005). The MAO-B suppression effect of Selegiline, a standard MAO-B inhibitor, was also studied using the same procedure, except that Selegiline was assayed instead of the plant extract.

\subsection{Stress exposure}

Since immobilization or restraint stress has been recognized as a valid test for studying stress-induced physical and psychological alterations and stressrelated disorders (Al-Mohaisen et al., 2000; Xu et al., 2006; Zaidi et al., 2014), it was used as the experimental model in this study. Immobilization stress was induced using a modified method of Retana-Márquez et al. (2003) and Ahmad et al. (2012). In brief, immobilization stress was applied between 6:00 a.m. and 6:00 p.m. The rats were put into a transparent perforated plastic tube $(20 \mathrm{~cm}$ long and $7 \mathrm{~cm}$ in diameter). Since the animal fitted tightly in the tube, it could not move or turn around.

\subsection{Male sexual behavior evaluation}

Fertile male Wistar rats were used as experimental animals. They were randomly divided into seven groups each with six animals. (1) Group I: naive control (non-stress group); rats received no treatment. (2) Group II: vehicle plus stress; rats were given the vehicle (DW) orally, 45 min before being subjected to $12 \mathrm{~h}$-restraint stress exposure for $7 \mathrm{~d}$. (3) Group III: sildenafil; this group served as a positive control based on the sexual enhancing effect of sildenafil citrate. All rats in this group were administered sildenafil citrate at a dose of $5 \mathrm{mg} / \mathrm{kg} 45 \mathrm{~min}$ before being subjected to $12 \mathrm{~h}$-restraint stress exposure for $7 \mathrm{~d}$. Since this drug has a maximum mode of action of $4 \mathrm{~h}$ after administration, an oral suspension of this drug at a dose of $5 \mathrm{mg} / \mathrm{kg}$ was given to all rats $1 \mathrm{~h}$ before the mating behavior assessment. (4) Group IV: tianeptine; this group also served as a positive control based on the dopamine enhancing effect of this drug (Invernizzi et al., 1992) and the positive modulation effect of dopamine on sexual dysfunction (El-Shafey et al., 2006). All rats in this group were given tianeptine orally at a dose of $15 \mathrm{mg} / \mathrm{kg} 45 \mathrm{~min}$ before being subjected to $12 \mathrm{~h}$-restraint stress exposure for $7 \mathrm{~d}$. (5) Groups V-VII: M. oleifera leaf extract treated groups; rats in these groups were given orally various doses of $M$. oleifera leaf extract, including 10,50 , and $250 \mathrm{mg} / \mathrm{kg} 45 \mathrm{~min}$ before being subjected to $12 \mathrm{~h}$-restraint stress exposure for $7 \mathrm{~d}$.

The treatments and the stress-exposure were carried out once daily. After being exposed to stress, the animals were given a $3 \mathrm{~h}$-refreshment period before their sexual behavior evaluation (Prabsattroo et al., 2012). The sexual behavior assessments were performed by an experienced observer blind to the treatments, at room temperature between 9:00 p.m. and 12:00 midnight after a single intervention and after one week of interventions.

Male rats subjected to single or repeated doses of the plant extract were paired with estrous female rats induced by estradiol benzoate (Sigma, St. Louis, MO, 
USA) at a dose of $2 \mu \mathrm{g} / \mathrm{kg}$ body weight (BW) and progesterone (Sigma, St. Louis, MO) at a dose of $500 \mu \mathrm{g} / \mathrm{kg}$ BW subcutaneously at 48 and $6 \mathrm{~h}$, respectively, before the determination of copulatory behavior. The sexual behavior of the rats in a clear plastic box was monitored for $3 \mathrm{~h}$ using video recording (Gauthaman et al., 2002). The assessed sexual parameters were latencies and frequencies of mounting, intromission, and ejaculation.

\subsection{Determination of PDE-5}

The level of PDE-5 was determined using a PDE-Glo ${ }^{\text {TM }}$ Phosphodiesterase Assay Kit (Promega Corp., Thailand). The penis was washed with phosphate buffer solution (PBS), cut into small pieces, and prepared as homogenate using lysate RIPA buffer. The sample was centrifuged at $14000 \mathrm{~g}$ at $4{ }^{\circ} \mathrm{C}$ for $15 \mathrm{~min}$. The supernatant was separated and served for the determination of PDE-5 activity. The PDE-Glo ${ }^{\mathrm{TM}}$ phosphodiesterase assay was carried out in a 96-well plate. The assay was performed according to the guidelines of the kit. In brief, the penis was incubated with cyclic guanosine monophosphate (cGMP) substrate in reaction buffer until the phosphodiesterse reaction was complete. PDE-Glo ${ }^{\mathrm{TM}}$ termination buffer was incubated with PDE detection solution containing adenosine triphosphate (ATP) and protein kinase A (PKA). The amount of ATP consumed by this reaction, which is directly correlated with the cGMP level, was evaluated using the luciferase-based Kinase-Glo reagent. After a 10-min incubation period at room temperature, the optical density of the sample was determined using a SpectraMax ${ }^{\circledR} \mathrm{L}$ microplate luminometer (MDS AT (US) Inc.) and expressed as relative light units (RLUs) and as a percentage of the control.

\subsection{Determination of testosterone and corti- costerone levels}

At the end of study, the venous blood of each animal was prepared as serum by centrifugation at $2000 \mathrm{~g}$ at $4{ }^{\circ} \mathrm{C}$ for $15 \mathrm{~min}$. The serum was stored at $-80{ }^{\circ} \mathrm{C}$ until used. Testosterone levels were measured using a radioimmunoassay (RIA) Kit (TESTO-CT2, Cisbio International, France) and corticosterone levels were measured using a Corticosterone Double Antibody Radioimmunoassay Kit (MP Biomedicals) for the quantitative determination of corticosterone in rat and mice serum. The results are expressed as $\mathrm{ng} / \mathrm{ml}$. Both assays were performed at the Radiology Department, Srinakarindhra Hospital, Faculty of Medicine, Khon Kaen University, Thailand.

\subsection{Histological study}

The testes were dissected out, freed from surrounding tissues and weighed quickly on a sensitive balance. They were fixed, embedded in paraffin, cut into $10 \mu \mathrm{m}$ thick sections, and stained using hematoxylin and eosin (H\&E). Histomorphological analysis was performed using a light microscope.

\subsection{Statistical analysis}

The experimental data are presented as mean \pm standard error of the mean (SEM). The statistical significance was evaluated using analysis of variance (ANOVA) followed by Duncan's test. A $P$-value of $<0.05$ was considered to be statistically significant.

\section{Results}

\subsection{Phenolic compound and flavonoid contents}

The total phenolic compounds in a $50 \%(\mathrm{v} / \mathrm{v})$ hydro-ethanolic extract of $M$. oleifera leaves were determined by the Folin-Ciocalteau method and expressed as GAE. The concentration of phenolics found in the M. oleifera leaf extract used in this study was $(62.333 \pm 0.008) \mathrm{mg} \mathrm{GAE} / \mathrm{g}$ extract. The flavonoid concentration of the extract was also determined using the aluminum chloride colorimetric method and was found to be $(29.900 \pm 0.001) \mathrm{mg} \mathrm{QE} / \mathrm{g}$ extract.

\subsection{DPPH radical scavenging activity and FRAP}

In this study, the $50 \%$ hydro-ethanolic extract of M. oleifera leaves was tested for its antioxidant scavenging effects on DPPH radicals. The results obtained at different concentrations of extract are given in Fig. 1. The results show that the extract showed dose-dependent activity. The concentration required for a $50 \%(\mathrm{v} / \mathrm{v}) \mathrm{DPPH}$ reduction (inhibitory concentration $50 \% ; \mathrm{IC}_{50}$ ) by the extract was determined using ascorbic acid as reference. The $\mathrm{IC}_{50}$ of ascorbic acid was $(0.124 \pm 0.009) \mathrm{mg} / \mathrm{ml}$, whereas that of the $M$. oleifera leaf extract was $(8.270 \pm$ $0.023) \mathrm{mg} / \mathrm{ml}$. 


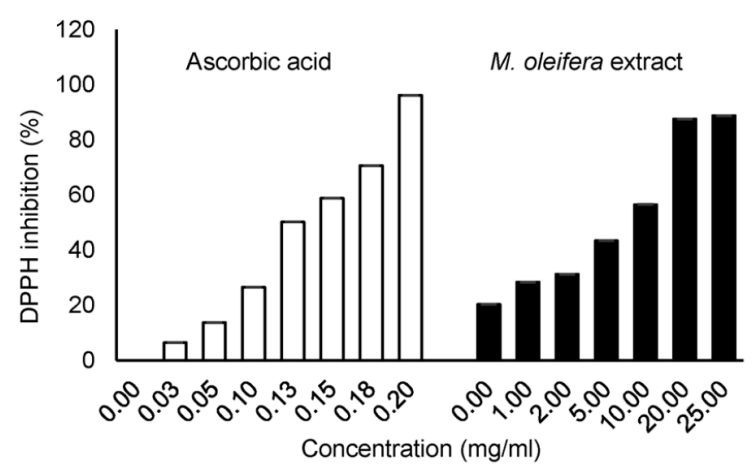

Fig. 1 DPPH radical scavenging activities of $M$. oleifera leaf extract and ascorbic acid (standard control)

Reducing power has been reported to be a validated indicator reflecting antioxidant activity (Oktay et al., 2003). The reducing power of M. oleifera leaf extract was assessed via an FRAP assay. The reducing power of the extract at various concentrations is shown in Fig. 2. The $\mathrm{IC}_{50}$ of the extract evaluated using the FRAP assay was $(399.00 \pm 0.010) \mu \mathrm{mol} / \mathrm{L}$ $\mathrm{AAE} / \mathrm{mg}$ extract.

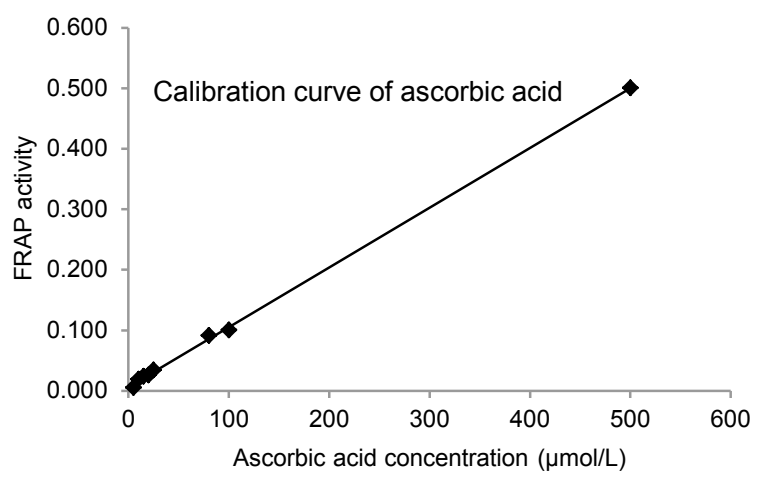

Fig. 2 Ferric reducing antioxidant power (FRAP) of M. oleifera leaf extract using ascorbic acid data to provide a calibration curve

FRAP activity of M. oleifera is $399 \mu \mathrm{mol} / \mathrm{L}$ AAE/mg extract

\subsection{Amino acid composition of $M$. oleifera leaf extract}

The amino acid composition of the leaf extract of $M$. oleifera is shown in Table 1. Phenylalanine showed the highest concentration $(2981.00 \mathrm{mg} / 100 \mathrm{~g})$. Serine, glutamic acid, leucine, lysine, isoleucine, tyrosine, histidine, valine, alanine, aspartic acid, proline, tryptophan, glycine, cysteine, methionine, threonine, arginine, hydroxylysine, and hydroxyproline were also observed.
Table 1 Amino acid profile of $M$. oleifera leaf extract detected by gas chromatography (ion exchange chromatographic method)

\begin{tabular}{lc||lr}
\hline Essential & $\begin{array}{c}\text { Concentration } \\
(\mathrm{mg} / 100 \mathrm{~g})\end{array}$ & Non-essential & $\begin{array}{r}\text { Concentration } \\
(\mathrm{mg} / 100 \mathrm{~g})\end{array}$ \\
\hline Alanine & 416.67 & Arginine & $<5.00$ \\
Histidine & 475.27 & Aspartic acid & 368.14 \\
Hydroxylysine & $<5.00$ & Cysteine & 133.39 \\
Isoleucine & 631.02 & Glutamic acid & 1422.00 \\
Leucine & 910.44 & Glycine & 131.33 \\
Lysine & 652.61 & Hydroxyproline & $<5.00$ \\
Methionine & 91.32 & Proline & 283.88 \\
Phenylalanine & 2981.00 & Serine & 1554.00 \\
Threonine & 79.72 & Tyrosine & 546.81 \\
Tryptophan & 263.80 & Valine & 422.97 \\
\hline
\end{tabular}

\subsection{MAO-B suppression effect of $M$. oleifera}

The MAO-B suppression effect of the extract was determined and used as an indicator to reflect the available dopamine, an important neurotransmitter which plays a pivotal role in male sexual function. The $\mathrm{IC}_{50}$ of MAO-B was $(0.255 \pm 0.008) \mathrm{mg} / \mathrm{ml}$ while that of selegiline, a standard MAO-B inhibitor, used for enhancing the dopamine level, was $(0.005 \pm$ $0.001) \mathrm{mg} / \mathrm{ml}$.

\subsection{Male sexual enhancing effect of $M$. oleifera leaf extract}

The effects of M. oleifera leaf extract on sexual behavior are presented in Table 2. The current data confirm the reputation of $M$. oleifera as a sexual stimulating agent. Rats that received either tianeptine (Group IV) or sildenafil citrate (Group III) and were subjected to the 12-h immobilization stress showed significantly decreased mounting latency $(P<0.05$, compared to vehicle control plus stress treated group (Group II) after a single intervention. However, only those rats in Group III showed a decreased intromission latency after the 7-d intervention period $(P<0.05$, compared to Group II). Unfortunately, no changes in latencies or the numbers of mounting, intromission, or ejaculation events were observed in rats of Group IV. After a single administration, rats treated with the extract at a dose of $50 \mathrm{mg} / \mathrm{kg}$ and exposed to immobilization stress (Group VI) showed a significantly decreased mounting latency $(P<0.05$, compared to Group II). Only rats subjected to the extract at a dose of $10 \mathrm{mg} / \mathrm{kg}$ and exposed to immobilization stress (Group V) significantly increased mounting numbers 
$(P<0.05$, compared to Group II) after a single administration. Interestingly, rats subjected to the extract at a dose of $10 \mathrm{mg} / \mathrm{kg}$ (Group V) and exposed to immobilization stress showed a significant decrease in intromission latency, but an increase in the number of intromissions $(P<0.05$, compared to Group II) after the 7-d intervention period. In addition, rats subjected to a high dose of extract plus stress (Group VII) also showed increased mounting numbers after the 7-d intervention period $(P<0.05$, compared to Group II). No significant changes in latency or the number of ejaculations were observed throughout the 7-d study period.

\subsection{PDE-5 activity of $M$. oleifera leaf extract}

PDE-5 activity in the penis of rats given $M$. oleifera leaf extract was determined (Fig. 3). The extract at a dose of $10 \mathrm{mg} / \mathrm{kg}$ significantly attenuated the enhanced PDE-5 activity in the penis of stress-exposed rats $(P<0.05$; compared to the control (Group I)). Both sildenafil citrate and tianeptine produced significant reductions in PDE-5 activity in the penis $(P<0.01$ and $P<0.05$, respectively; compared to Group II). Rats in Group V showed a significant decrease in PDE-5 activity in the penis $(P<0.05$; compared to Group II).

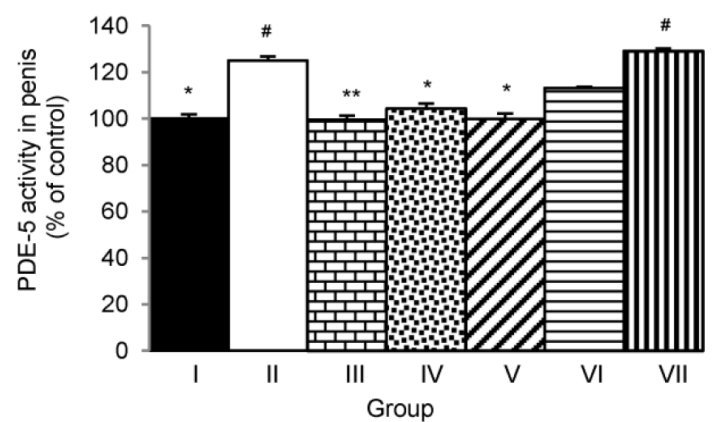

Fig. 3 Effect of hydro-ethanolic extracts of $M$. oleifera leaves on phosphodiesterase type 5 (PDE-5) activity in the penis of stress-exposed rats after $7 \mathrm{~d}$ of treatment

Data are expressed as mean $\pm \operatorname{SEM}(n=6) .{ }^{*} P<0.05,{ }^{* *} P<0.01$, compared with Group II. ${ }^{\#} P<0.05$, compared with Group I

Table 2 Effect of hydro-alcoholic extracts of $M$. oleifera leaves on male sexual behavior of stress-exposed rats at baseline, after a single dose, and after $7 \mathrm{~d}$ of treatment

\begin{tabular}{ccccccc}
\hline Group & ML (s) & MN & IL (s) & IN & EL (s) & EF \\
\hline Baseline & & & & & & \\
I & $15.6 \pm 10.7$ & $29.2 \pm 5.2$ & $102.5 \pm 64.4$ & $23.2 \pm 2.9$ & $582.3 \pm 114.8$ & $2.3 \pm 0.5$ \\
II & $13.0 \pm 3.3$ & $31.0 \pm 2.0$ & $292.6 \pm 257.0$ & $17.2 \pm 4.2$ & $1026.6 \pm 318.7$ & $1.6 \pm 0.7$ \\
III & $33.0 \pm 12.2$ & $44.3 \pm 6.2$ & $155.8 \pm 86.2$ & $18.3 \pm 3.1$ & $946.5 \pm 198.7$ & $1.5 \pm 0.3$ \\
IV & $11.5 \pm 4.8$ & $38.2 \pm 6.7$ & $45.0 \pm 8.3$ & $23.2 \pm 1.5$ & $750.8 \pm 218.1$ & $1.8 \pm 0.4$ \\
V & $20.5 \pm 10.9$ & $34.0 \pm 5.1$ & $149.6 \pm 65.6$ & $14.5 \pm 2.3$ & $707.0 \pm 78.3$ & $1.4 \pm 0.4$ \\
VI & $19.7 \pm 7.5$ & $32.2 \pm 5.2$ & $173.3 \pm 86.1$ & $22.4 \pm 3.2$ & $1015.1 \pm 268.3$ & $2.0 \pm 0.7$ \\
VII & $29.8 \pm 13.8$ & $34.7 \pm 3.3$ & $68.7 \pm 26.5$ & $21.7 \pm 3.7$ & $1143.8 \pm 163.4$ & $1.3 \pm 0.4$ \\
Single dose & & & & & \\
I & $15.7 \pm 8.0$ & $39.0 \pm 6.3$ & $38.7 \pm 8.3$ & $27.6 \pm 5.0$ & $613.0 \pm 129.9$ & $2.0 \pm 0.4$ \\
II & $29.0 \pm 11.2$ & $32.2 \pm 3.7$ & $111.4 \pm 70.2$ & $26.2 \pm 5.2$ & $326.6 \pm 196.5$ & $2.2 \pm 0.2$ \\
III & $3.2 \pm 0.9^{*}$ & $37.5 \pm 5.1$ & $75.3 \pm 24.2$ & $20.7 \pm 2.9$ & $568.3 \pm 139.8$ & $2.7 \pm 0.5$ \\
IV & $6.0 \pm 2.3^{*}$ & $28.8 \pm 6.4$ & $38.3 \pm 8.7$ & $23.7 \pm 3.1$ & $502.3 \pm 87.1$ & $2.0 \pm 0.3$ \\
V & $28.6 \pm 7.3$ & $49.8 \pm 6.4^{*}$ & $78.0 \pm 21.8$ & $21.2 \pm 2.8$ & $447.4 \pm 62.9$ & $2.5 \pm 0.3$ \\
VI & $6.4 \pm 2.0^{*}$ & $44.8 \pm 6.2$ & $58.6 \pm 20.1$ & $22.0 \pm 4.5$ & $883.2 \pm 137.3$ & $1.3 \pm 0.3$ \\
VII & $34.6 \pm 11.3$ & $41.0 \pm 7.1$ & $46.3 \pm 13.8$ & $17.6 \pm 4.3$ & $895.2 \pm 254.4$ & $1.4 \pm 0.4$ \\
7-d & & & & & \\
I & $2.0 \pm 0.8$ & $31.0 \pm 1.5$ & $15.0 \pm 3.8^{*}$ & $29.8 \pm 1.9^{*}$ & $421.5 \pm 112.5$ & $2.5 \pm 0.2$ \\
II & $15.8 \pm 7.7$ & $28.2 \pm 4.0$ & $81.8 \pm 49.7^{\#}$ & $20.3 \pm 3.9^{\#}$ & $482.5 \pm 225.1$ & $2.4 \pm 0.4$ \\
III & $3.3 \pm 1.3$ & $33.8 \pm 4.9$ & $13.8 \pm 3.2^{*}$ & $29.2 \pm 1.4^{*}$ & $319.7 \pm 137.6$ & $3.0 \pm 0.4$ \\
IV & $18.2 \pm 7.3$ & $33.7 \pm 7.9$ & $47.3 \pm 9.5$ & $26.2 \pm 1.2$ & $639.0 \pm 55.4$ & $2.3 \pm 0.2$ \\
V & $14.2 \pm 7.4$ & $29.7 \pm 2.4$ & $12.6 \pm 4.4^{*}$ & $32.7 \pm 3.0^{* *}$ & $397.8 \pm 44.5$ & $2.2 \pm 0.2$ \\
VI & $15.2 \pm 6.9$ & $44.4 \pm 6.6$ & $27.8 \pm 10.8$ & $23.6 \pm 3.0$ & $672.3 \pm 243.9$ & $2.0 \pm 0.6$ \\
VII & $18.2 \pm 7.2$ & $46.2 \pm 9.2^{*}$ & $39.8 \pm 14.2$ & $24.6 \pm 4.3$ & $711.8 \pm 111.8$ & $1.8 \pm 0.2$ \\
\hline VI & & & & & \\
\end{tabular}

ML: mount latency; MN: mount number; IL: intromission latency; IN: intromission number; EL: ejaculation latency; EF: ejaculation frequency. Data are expressed as mean $\pm \operatorname{SEM}(n=6) .{ }^{*} P<0.05,{ }^{* *} P<0.01$, compared with Group II. ${ }^{\#} P<0.05$, compared with Group I 


\subsection{Effect of M. oleifera leaf extract on testos- terone and corticosterone levels}

Fig. 4 shows that the male rats receiving sildenafil citrate and $M$. oleifera leaf extract at doses of 10 and $250 \mathrm{mg} / \mathrm{kg}$ and exposed to immobilization stress for $7 \mathrm{~d}$ showed elevated levels of serum testosterone $(P<0.001, P<0.05$, and $P<0.01$, respectively; compared to Group II). We also evaluated the effect of the extract on the serum corticosterone level (Fig. 5). Rats subjected to the extract treatment at doses of 10,50 , and $250 \mathrm{mg} / \mathrm{kg}$ and exposed to immobilization stress for $7 \mathrm{~d}$ showed elevated serum corticosterone levels $(P<0.01, P<0.001$, and $P<0.05$, respectively; compared to Group II).

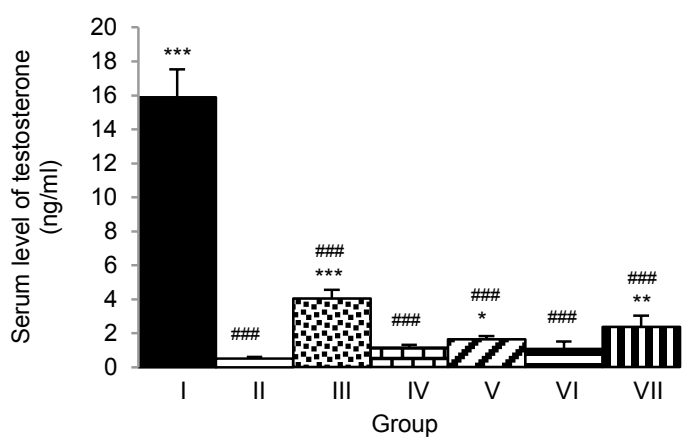

Fig. 4 Effect of hydro-ethanolic extracts of $M$. oleifera leaves on serum testosterone levels of stress-exposed rats after $7 \mathrm{~d}$ of treatment

Data are expressed as mean $\pm \operatorname{SEM}(n=6) .{ }^{*} P<0.05,{ }^{* *} P<0.01$,

${ }^{* * *} P<0.001$, compared with Group II. ${ }^{\# \#} P<0.001$, compared with Group I
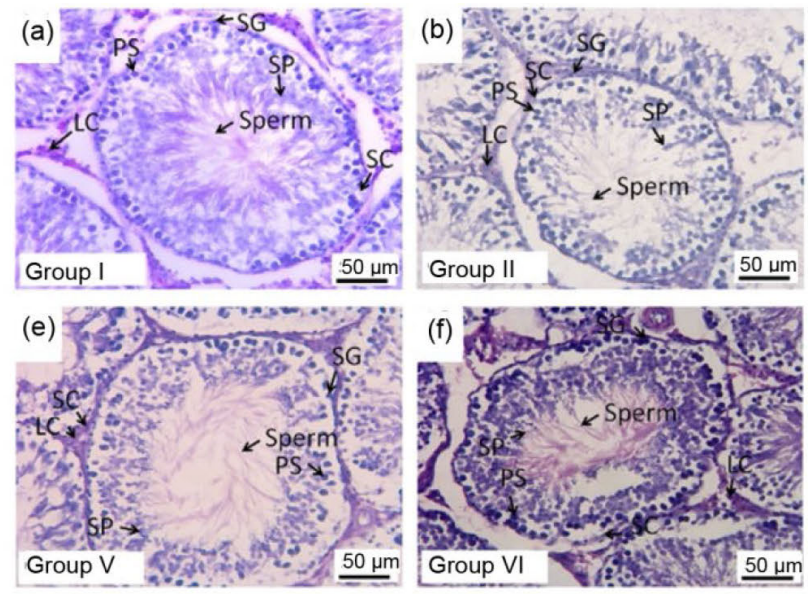

\subsection{Effect of $M$. oleifera leaf extract on testis histology}

The histological morphology of the testis was evaluated and the results are shown in Fig. 6. In the vehicle plus stress treated group (Group II), the seminiferous epithelium was disorganized and fewer interstitial cells of Leydig were observed. Rats subjected to stress and sildenafil, or stress plus tianeptine, or stress plus M. oleifera extract at doses used in this study showed a more organized seminiferous epithelium than those in Group II. In addition, rats in all these groups appeared to have more interstitial cells of Leydig and more spermatozoa in the lumen of the seminiferous tubules than those in Group II.

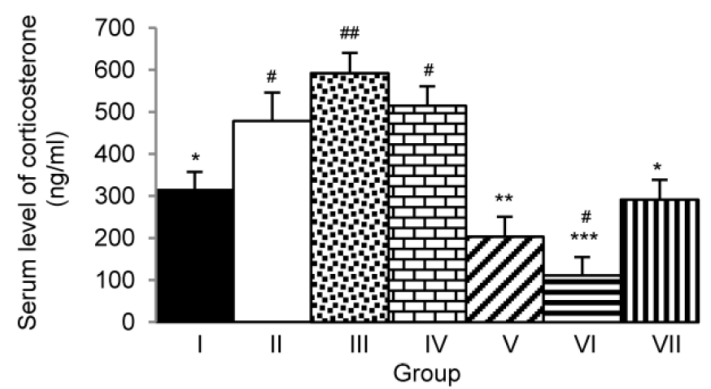

Fig. 5 Effect of hydro-ethanolic extracts of $M$. oleifera leaves on serum corticosterone levels of stress-exposed rats after $7 \mathrm{~d}$ of treatment

Data are expressed as mean $\pm \operatorname{SEM}(n=6) .{ }^{*} P<0.05,{ }^{* *} P<0.01$, ${ }^{* * *} P<0.001$, compared with Group II. ${ }^{\#} P<0.05$, ${ }^{\#} P<0.01$, compared with Group I
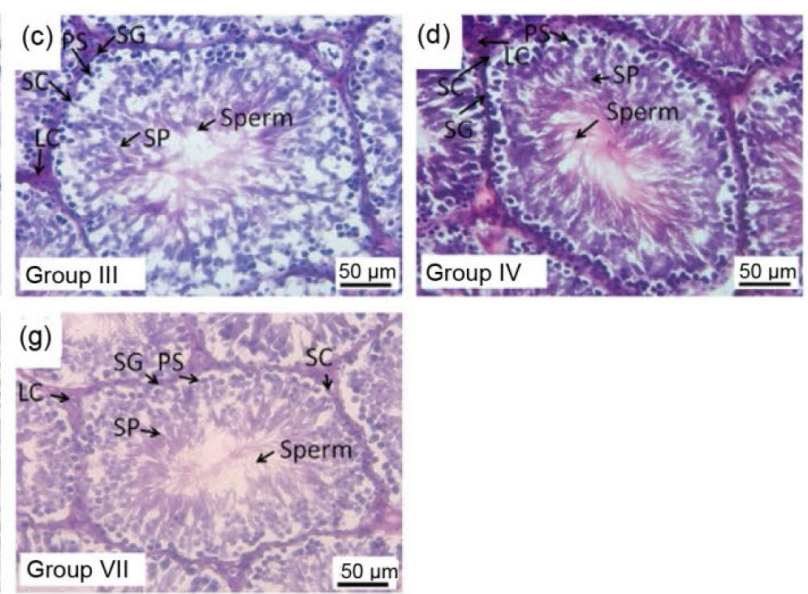

Fig. 6 Haematoxylin and eosin (H\&E) stained frozen sections of rat testis showing the histomorphology of seminiferous tubules, Sertoli cells (SC), spermatogonia (SG), primary spermatocytes (PS), spermatids (SP), sperm, and Leydig cells (LC) in the following treatment groups: (a) naive control; (b) vehicle plus stress; (c) sildenafil citrate plus stress; (d) Tianeptine plus stress; (e)-(g) M. oleifera at doses of 10, 50, and $250 \mathrm{mg} / \mathrm{kg}$ plus stress, respectively 


\section{Discussion}

The current study has revealed that $M$. oleifera leaf extract has antioxidant and MAO-B suppression effects. Phenylalanine was the main amino acid found in the extract. In vivo data showed that a single consumption of medium or low doses of extract increased libido. When the treatment was prolonged to $7 \mathrm{~d}$, the low dose of extract enhanced penile erection capacity by decreasing intromission latency and increasing intromission number, decreased both PDE-5 activity and corticosterone levels, increased the numbers of interstitial cells of Leydig and spermatozoa, and increased testosterone levels. The high dose extract also increased the numbers of mountings, interstitial cells of Leydig and spermatozoa, increased testosterone levels, and reduced corticosterone levels.

Male sexual behavior is governed by a complex interaction between different systems in the brain that process sensory inputs, regulate reward and motivation, and integrate hormonal signals (Hull et al., 2004). The regulation of sexual behavior can occur both at the brain and at peripheral sites. It has been reported that testosterone plays an important role in priming brain neural circuits for sexual behavior. The priming effect is achieved partly by the modification of regulating enzymes, receptors, or other proteins which affect neurotransmitter function. Testosterone can increase local dopamine synthesis and metabolism of dopamine (Purves-Tyson et al., 2012), which in turn exerts an influence on various aspects of male sexual function including sexual motivation, copulatory proficiency, and genital reflexes (Hull et al., 2004).

Accumulated evidence has shown that dopamine plays a crucial role in male sexual behavior via the enhanced release of oxytocin from the paraventricular nucleus (PVN) of the hypothalamus, which in turn increases the release of nitric oxide from the carvernosal nerve. Nitric oxide penetrates the cytoplasm of smooth muscle cells and interacts with guanylyl cyclase, catalyzing conformational changes which in turn induce the conversion of guanosine 5'-triphosphate (GTP) to 3'-5'-cyclic guanosine monophosphate. cGMP in turn phosphorylates several proteins, resulting in decreased intracellular calcium levels causing the relaxation of arterial and trabecular smooth muscle, resulting in arterial dilata- tion, venous constriction, and the rigidity of penile erection. The inactivation of cGMP via PDE-5 decreases the dilation of arterial vessels and the constriction of venous blood vessels and increases penile tumescence (Andersson, 2001).

In this study, stress exposure induced a reduction in the number of interstitial cells of Leydig and in serum testosterone levels. These changes may possibly have been due to enhanced oxidative stress (Rai et al., 2004; Bitgul et al., 2013). M. oleifera extract attenuated the reduction in the interstitial cells of Leydig and serum testosterone levels induced by stress exposure. Based on the results of this study, we suggest that the antioxidant effect of the extract alleviates oxidative stress-related cell toxicity, resulting in increased numbers of interstitial cells of Leydig and serum testosterone levels. It has been reported that the elevation of glucocorticoid levels induced by stress can also inhibit the synthesis of testosterone in interstitial cells of Leydig (Gao et al., 1996). Therefore, the mitigating effect of $M$. oleifera extract on the reduction in testosterone induced by stress may occur partly via decreased corticosterone levels.

It has been shown that $M$. oleifera extract also suppresses MAO-B. Due to the crucial role of dopamine in male sexual behavior mentioned earlier, it is possible that suppression of MAO-B activity may enhance the available dopamine, which in turn increases oxytocin release from the PVN and induces the release of nitric oxide from the carvernosal nerve, triggering the elevation of cGMP in the penis. The elevation of cGMP induced by $M$. oleifera extract and the suppression effect of the extract on PDE-5 may enhance the cGMP-dependent vasodilation effect of nitric oxide, leading to enhanced penile blood flow and erection. Since the high dose of $M$. oleifera extract failed to show a PDE-5 suppression effect, no significant change in the intromission phase was observed in stress-exposed rats that received a high dose of extract. In addition, it has been reported that the elevation of testosterone can regulate PDE-5 function (Aversa et al., 2009) and modify dopamine inactivation via $\mathrm{MAO}-\mathrm{B}$, leading to increased penile erection (Sanna et al., 2011). Therefore, the enhanced intromission phase observed in this study may have been related to MAO-B suppression activity, the ability to increase the testosterone level or the PDE-5 suppression effect. 
In this study, an increased number of spermatozoa was also observed in stress-exposed rats subjected to M. oleifera leaf extract treatment. It has been reported that spermatozoa are vulnerable to oxidative stress because of the high concentration of polyunsaturated fatty acids involved in the regulation of sperm maturation, spermatogenesis, capacitation, acrosome reaction, and eventually membrane fusion, and their low antioxidant capacity. An attack of oxidative stress may lead to structural damage and decreased viability. Therefore, the increased spermatozoa density induced by the $M$. oleifera leaf extract may possibly be due to the antioxidant effect of the extract.

Our data also suggest that the enhanced dopaminergic function induced by the $M$. oleifera leaf extract may occur not only via the MAO-B suppression effect but also via the high concentration of phenylalanine in the plant extract. Since phenylalanine serves as a precursor for tyrosine and dopamine synthesis, the enhanced dopamine function observed in this study may also occur partly via the increased dopamine precursor supplement. Moreover, the $M$. oleifera leaf extract used in this study also contained abundant phenolics and flavonoids. Therefore, the antioxidant effect of the extract may have been due to these ingredients.

This study is the first to demonstrate the possible benefit of $M$. oleifera active amino acids on dopaminergic and sexual function besides the possible role of phenolics and flavonoids in the extract, and the biochemical and histological changes related to stress and sexual function. However, the determination of the effect of the plant extract on serum testosterone and PDE-5 activity in the penis at only a single time point and the lack of nitric oxide and penile vascular blood flow measurement, were limitations of this study. The effect of the plant extract on serum testosterone before and during sexual performance should be determined to confirm the modulating role of the extract on the sexual enhancement effect of testosterone. The effect of the extract on PDE-5 activity in testis both before and during the sexual intromission phase should also be determined together with the levels of nitric oxide, cGMP, and penile blood flow, to confirm that the suppression of PDE-5 induced by the plant extract can enhance the cGMP-dependent vasodilation effects of nitric oxide, penile blood flow, and penile erection.
Therefore, further investigations of the effect of M. oleifera leaf extract on the alterations of testosterone and dopamine levels before and during sexual performance, together with evaluation of the cGMPdependent vasodilation effects of nitric oxide, penile blood flow and penile erection, are required to improve understanding of the precise underlying mechanisms of the sexual enhancing effect of $M$. oleifera leaf extracts.

\section{Conclusions}

The use of Moringa oleifera leaf extract may provide a cheap and simple approach for improving sexual function under stressful conditions. Therefore, the extract appears to be a potential aphrodisiac, particularly for people with stressful daily lifestyles. However, more research is needed concerning the possible underlying mechanisms of action of $M$. oleifera leaf extracts, such as the determination of testosterone levels before and during sexual performance, and the evaluation of the cGMP-dependent vasodilation effects of nitric oxide, penile blood flow, and penile erection.

\section{Acknowledgements}

We would like to express our sincere thanks to Assoc. Prof. Panee SIRISA-ARD (Faculty of Pharmacy, Chiangmai University, Thailand) for her authentication.

\section{Compliance with ethics guidelines}

Thawatchai PRABSATTROO, Jintanaporn WATTANATHORN, Sitthichai IAMSAARD, Pichet SOMSAPT, Opass SRITRAGOOL, Wipawee THUKHUMMEE, and Supaporn MUCHIMAPURA declare that they have no conflict of interest.

All institutional and national guidelines for the care and use of laboratory animals were followed.

\section{References}

Ahmad, A., Rasheed, N., Gupta, P., et al., 2012. Novel Ocimumoside A and B as anti-stress agents: modulation of brain monoamines and antioxidant systems in chronic unpredictable stress model in rats. Phytomedicine, 19(7): 639-647. [doi:10.1016/j.phymed.2012.02.012]

Al-Mohaisen, M., Cardounel, A., Kalimi, M., 2000. Repeated immobilization stress increases total cytosolic glucocorticoid receptor in rat liver. Steroids, 65(1):8-15. [doi:10. 1016/S0039-128X(99)00076-8]

Andersson, K.E., 2001. Pharmacology of penile erection. Pharmacol. Rev., 53(3):417-450. 
Aversa, A., Bruzziches, R., Francomano, D., et al., 2009. Testosterone and phosphodiesterase type-5 inhibitors: new strategy for preventing endothelial damage in internal and sexual medicine. Ther. Adv. Urol., 1(4):179-197. [doi:10.1177/1756287209344992]

Baldwin, D.S., 2001. Depression and sexual dysfunction. Br. Med. Bull., 57(1):81-99. [doi:10.1093/bmb/57.1.81]

Basma, A.A., Zakaria, Z., Latha, L.Y., et al., 2011. Antioxidant activity and phytochemical screening of the methanol extracts of Euphorbia hirta L. Asian Pac. J. Trop. Med., 4(5):386-390. [doi:10.1016/S1995-7645(11)60109-0]

Bitgul, G., Tekmen, I., Keles, D., et al., 2013. Protective effects of resveratrol against chronic immobilization stress on testis. ISRN Urol., 2013:278720. [doi:10.1155/2013/ 278720]

Carrasco, G.A., van de Kar, L.D., 2003. Neuroendocrine pharmacology of stress. Eur. J. Pharmacol., 463(1-3): 235-272. [doi:10.1016/S0014-2999(03)01285-8]

de Ancos, B., Sgroppo, S., Plaza, L., et al., 2002. Possible nutritional and health-related value promotion in orange juice preserved by high-pressure treatment. J. Sci. Food Agric., 82(8):790-796. [doi:10.1002/jsfa.1093]

de Young, L., Yu, D., Bateman, R.M., et al., 2004. Oxidative stress and antioxidant therapy: their impact in diabetesassociated erectile dysfunction. J. Androl., 25(5):830-836 [doi:10.1002/j.1939-4640.2004.tb02862.x]

Dhingra, D., Goyal, P.K., 2008. Evidences for the involvement of monoaminergic and GABAergic systems in antidepressant-like activity of Tinospora cordifolia in mice. Indian J. Pharm. Sci., 70(6):761-767. [doi:10.4103/0250474X.49118]

El-Shafey, H., Atteya, A., el-Magd, S.A., et al., 2006. Tianeptine can be effective in men with depression and erectile dysfunction. J. Sex. Med., 3(5):910-917. [doi:10. 1111/j.1743-6109.2005.00141.x]

Fauci, A.S., Wiener, C.M., Brown, C., 2005. Harrison's Principles of Internal Medicine, 16th Ed. McGraw-Hill, Medical Pub. Division.

Ganguly, R., Guha, D., 2008. Alteration of brain monoamines \& EEG wave pattern in rat model of Alzheimer's disease \& protection by Moringa oleifera. Indian J. Med. Res., 128(6):744-751.

Gao, H.B., Shan, L.X., Monder, C., et al., 1996. Suppression of endogenous corticosterone levels in vivo increases the steroidogenic capacity of purified rat Leydig cells in vitro. Endocrinology, 137(5):1714-1718. [doi:10.1210/endo.137. 5.8612506]

Gauthaman, K., Adaikan, P.G., Prasad, R.N.V., 2002. Aphrodisiac properties of Tribulus terrestris extract (protodioscin) in normal and castrated rats. Life Sci., 71(12):13851396. [doi:10.1016/S0024-3205(02)01858-1]

Hamed, E., Meki, A., Gaafar, A., et al., 2003. Role of some vasoactive mediators in patients with erectile dysfunction their relationship with angiotensin-converting enzyme and growth hormone. Int. J. Impot. Res., 15(6):418-425. [doi:10.1038/sj.ijir.3901059]
Holt, A., Sharman, D.F., Baker, G.B., et al., 1997. A continuous spectrophotometric assay for monoamine oxidase and related enzymes in tissue homogenates. Anal. Biochem., 244(2):384-392. [doi:10.1006/abio.1996.9911]

Hull, E.M., Du, J., Lorrain, D.S., et al., 1997. Testosterone, preoptic dopamine, and copulation in male rats. Brain Res. Bull., 44(4):327-333. [doi:10.1016/S0361-9230(97)002 11-6]

Hull, E.M., Muschamp, J.W., Sato, S., 2004. Dopamine and serotonin: influences on male sexual behavior. Physiol. Behav., 83(2):291-307. [doi:10.1016/j.physbeh.2004.08. 018]

Invernizzi, R., Pozzi, L., Garattini, S., et al., 1992. Tianeptine increases the extracellular concentrations of dopamine in the nucleus accumbens by a serotonin-independent mechanism. Neuropharmacology, 31(3):221-227. [doi:10. 1016/0028-3908(92)90171-K]

Kennedy, S.H., Dickens, S.E., Eisfeld, B.S., et al., 1999. Sexual dysfunction before antidepressant therapy in major depression. J. Affect. Disord., 56(2):201-208. [doi:10. 1016/S0165-0327(99)00050-6]

Kothari, P., 2001. Common Sexual Problems, 3rd Ed. UBS Publishers Distributors (P), Ltd., New Delhi, India.

Lewis, R.W., Fugl-Meyer, K.S., Bosch, R., et al., 2004. Epidemiology/risk factors of sexual dysfunction. J. Sex. Med., 1(1):35-39. [doi:10.1111/j.1743-6109.2004.10106.x]

Makonnen, E., Hunde, A., Damecha, G., 1997. Hypoglycaemic effect of Moringa stenopetala aqueous extract in rabbits. Phytother. Res., 11(2):147-148. [doi:10.1002/ (SICI)1099-1573(199703)11:2<147::AID-PTR41>3.0.C $\mathrm{O} ; 2-\mathrm{V}]$

Meston, C.M., Frohlich, P.F., 2000. The neurobiology of sexual function. Arch. Gen. Psychiatry, 57(11):10121030. [doi:10.1001/archpsyc.57.11.1012]

Minhas, S., Jeremy, J.Y., Jones, R.W.A., et al., 2002. Oxygen free radicals and the penis. Expert Opin. Pharmacother., 3(7):889-897. [doi:10.1517/14656566.3.7.889]

Monera, T.G., Wolfe, A.R., Maponga, C.C., et al., 2008. Moring a oleifera leaf extracts inhibit 6 $\beta$-hydroxylation of testosterone by CYP3A4. J. Infect. Dev. Ctries., 2(5):379383. [doi:10.3855/jidc.201]

Nwidu, L.L., Cilli, E.M., Vilegas, W., 2012. Amino acid, antioxidant and ion profiles of Carpolobia lutea leaf (Polygalaceae). Tropical J. Pharm. Res., 11(5):807-813. [doi:10.4314/tjpr.v11i5.15]

Oktay, M., Gülçin, İ., Küfrevioğlu, Ö.İ., 2003. Determination of in vitro antioxidant activity of fennel (Foeniculum vulgare) seed extracts. LWT-Food Sci. Technol., 36(2): 263-271. [doi:10.1016/S0023-6438(02)00226-8]

Orr, T.E., Mann, D.R., 1990. Effects of restraint stress on plasma LH and testosterone concentrations, Leydig cell LH/HCG receptors, and in vitro testicular steroidogenesis in adult rats. Horm. Behav., 24(3):324-341. [doi:10.1016/ 0018-506X(90)90013-N]

Pourmorad, F., Hosseinimehr, S.J., Shahabimajd, N., 2006. Antioxidant activity, phenol and flavonoid contents of 
some selected Iranian medicinal plants. Afr. J. Biotechnol., 5(11):1142-1145. [doi:10.5897/AJB06.168]

Prabsattroo, T., Wattanathorn, J., Iamsa-ard, S., et al., 2012. Moringa oleifera leaves extract attenuates male sexual dysfunction. Am. J. Neurosci., 3(1):17-24. [doi:10.3844/ amjnsp.2012.17.24]

Purves-Tyson, T., Handelsman, D., Double, K., et al., 2012. Testosterone regulation of sex steroid-related mRNAs and dopamine-related mRNAs in adolescent male rat substantia nigra. BMC Neurosci., 13(1):95. [doi:10.1186/ 1471-2202-13-95]

Rai, J., Pandey, S.N., Srivastava, R.K., 2004. Testosterone hormone level in albino rats following restraint stress of long duration. J. Anat. Soc. India, 53(1):17-19.

Retana-Márquez, S., Bonilla-Jaime, H., Vazquez-Palacios, G., et al., 2003. Changes in masculine sexual behavior, corticosterone and testosterone in response to acute and chronic stress in male rats. Horm. Behav., 44(4):327-337. [doi:10.1016/j.yhbeh.2003.04.001]

Sanna, F., Succu, S., Hübner, H., et al., 2011. Dopamine D2-like receptor agonists induce penile erection in male rats: differential role of D2, D3 and D4 receptors in the paraventricular nucleus of the hypothalamus. Behav. Brain Res., 225(1):169-176. [doi:10.1016/j.bbr.2011.07.018]

Santosh, B.T., Chitme, H.R., Rabbani, G., et al., 2011. Effect of Leptadenia reticulata Linn. on stress modulated sexual behavior of male rats. Int. Res. J. Pharm., 2(10):27-36.

Schurr, A., Livne, A., 1976. Differential inhibition of mitochondrial monoamine oxidase from brain by hashish components. Biochem. Pharmacol., 25(10):1201-1203. [doi:10.1016/0006-2952(76)90369-5]

Sreelatha, S., Padma, P.R., 2009. Antioxidant activity and total phenolic content of Moringa oleifera leaves in two stages of maturity. Plant Foods Hum. Nutr., 64(4):303-311. [doi:10.1007/s11130-009-0141-0]

Thaipong, K., Boonprakob, U., Crosby, K., et al., 2006. Comparison of ABTS, DPPH, FRAP, and ORAC assays for estimating antioxidant activity from guava fruit extracts. J. Food Compost. Anal., 19(6-7):669-675. [doi:10.1016/j.jfca.2006.01.003]

Xu, J.K., Hiroshi, K., Zheng, J.J., et al., 2006. Protective effect of tanshinones against liver injury in mice loaded with restraint stress. Acta Pharm. Sin., 41(7):631-635 (in Chinese). $\mathrm{Xu}$, Y., Ku, B.S., Yao, H.Y., et al., 2005. The effects of curcumin on depressive-like behaviors in mice. Eur. J. Pharmacol., 518(1):40-46. [doi:10.1016/j.ejphar.2005.06. 002]

Zaidi, S.K., Hoda, M.N., Tabrez, S., et al., 2014. Protective effect of Solanum nigrum leaves extract on immobilization stress induced changes in rat's brain. Evid. Based Complement. Alternat. Med., 2014:912450. [doi:10.1155/ 2014/912450]

Zhang, Q., Radisavljevic, Z.M., Siroky, M.B., et al., 2011. Dietary antioxidants improve arteriogenic erectile dysfunction. Int. J. Androl., 34(3):225-235. [doi:10.1111/j. 1365-2605.2010.01083.x]

\section{中文概要}

\section{题 目: 辣木提取物对应激大鼠性能力具有增强作用}

目 的: 探讨辣木叶提取物对改善应激条件下雄性性功能 障碍的作用。

创新点：根据氧化应激和多巴胺对雄性性功能的影响, 推 测具有抗氧化和单胺调节功能的辣木叶能改善应 激条件下的雄性性功能障碍。

方 法: 本文以雄性 Wistar 大鼠作为实验对象, 通过对影 响雄性性功能的各种因素进行测量及统计学分析, 包括抗氧化性、B 型单胺氧化酶 (MAO-B) 和 5 型磷酸二酷酶 (PDE-5) 活性、血清睪酮和皮质 甾酮水平、睪丸内组织形态学变化。

结 论: 研究结果表明, 辣木叶提取物作为一种抗氧化剂 具有抑制 MAO-B 和 PDE-5 活性的作用, 同时能 降低血清皮质酮水平, 提高血清睪酮水平, 增加 睪丸间质细胞和精子的数量。睪丸间质细胞和精 子的数量的增加可能是由于辣木叶提取物的抗氧 化作用, 插入阶段性功能增强可能是由于 MAO-B 和 PDE-5 活性的抑制和睪酮水平的增加。因此, 辣木可以作为一种潜在的壮阳药。

关键词: 辣木; 性功能; 应激 